\title{
Systemic arterial hypertension and flight
}

\author{
Kaan Okyay (D)
}

Department of Cardiology, Faculty of Medicine, Başkent University; Ankara-Turkey

\section{ABSTRACT}

Hypertension is the major preventable cause of cardiovascular disease and all-cause death. Given its overall high prevalence, hypertension would be one of our major concerns in commercial flights. Hence, the management of hypertension is of great importance. Herein, we discuss the pathophysiological factors for elevated blood pressure during flight, and we make recommendations which should be followed by the passengers and the flight crew and the physicians for trouble-free air travel.

Keywords: hypertension, management, air travel

\section{Introduction}

Conventionally, hypertension is defined as office systolic blood pressure (SBP) values $\geq 140 \mathrm{~mm} \mathrm{Hg}$ and/or diastolic blood pressure (DBP) values $\geq 90 \mathrm{~mm} \mathrm{Hg}$ or requiring antihypertensive medication (1). On the basis of office BP, approximately 1.13 billion people were affected by hypertension in 2015 , and hypertension is the major preventable cause of cardiovascular disease (CVD) and all-cause death (2). In the PatenT2 (the prevalence, awareness, treatment, and control of hypertension in Turkey) trial, the overall age and sex-adjusted prevalence of hypertension was found as $30.3 \%$ (3).

Approximately, 40 million people use commercial flights annually (4). It is estimated that by 2030, half of the passengers in commercial flights will be over 50 years of age because of increased life spans. At the same time, our ability to care for patients with cardiac diseases and advancement in flying technology improve continuously. Accordingly, we can predict a higher number of "older" individuals or those with cardiac diseases will travel in commercial flights (5). Given its overall prevalence mentioned above, hypertension would be one of our major concerns. The management of hypertension should be considered, both for the passengers and the flight crew.

The main pathophysiological factor during a flight is altitude related decrease in oxygen saturation. Commercial airplanes fly at $30,000-40,000$ feet (corresponding to $9,000-12,000 \mathrm{~m}$ ) above the sea level. However, commercial flights maintain a relative cabin altitude between 5,000 and 8,000 feet during routine flights. However, at this altitude, the barometric pressure decreases from a normal sea level value of 760 to $560 \mathrm{~mm} \mathrm{Hg}$. This pressure change is related to the decrease in arterial oxygen tension, which is well tolerated in healthy individuals but might trigger ischemia and arrhythmia in susceptible patients. The inspired $\mathrm{PO}_{2}$ falls by $4 \mathrm{~mm} \mathrm{Hg}$ per 1,000 feet above sea level. Consequently, the patients with concomitant pulmonary diseases such as chronic obstructive pulmonary disease and pulmonary hypertension may require supplemental oxygen during travel. In addition, some patients with cardiovascular diseases such as severe left and/or right ventricular dysfunction and congenital heart diseases can be more sensitive to changes in arterial oxygen saturation $(4,6,7)$. The details of acute and chronic cardiovascular changes for adaption to high altitude will not be mentioned in detail. Basically, an increase in heart rate, cardiac contractility, and cardiac output could alter systemic blood pressure. Hypoxia triggers peripheral vasodilatation and activation of the sympathetic nervous system. In patients with hypertension, however, endothelial dysfunction may inhibit hypoxic vasodilatation and even induce peripheral vasoconstriction. In healthy individuals, these mechanisms overall result in a nonsignificant increase of blood pressure, but with high inter-individual variability. Only a modest increase was observed in patients with controlled blood pressure (8-10). However, there is still a potential risk for significant elevation in systemic arterial pressure in those with uncontrolled blood pressure. Stressful factors related to flight such as increased anxiety especially during take-off and landing, changes in body position induced by

Address for Correspondence: Dr. Kaan Okyay, Department of Cardiology,

Faculty of Medicine, Başkent University; Ankara-Turkey

Phone: +90 5327343339 E-mail: drokyay@yahoo.com 
Table 1. General recommendations for air travelers with hypertension $(7,8,16,17)$

- Blood pressure should preferably be controlled before traveling.

- Medications sufficient for the length of travel should be available in carry-on luggage.

- Medications should be managed with following physician before flights with risk of circadian dysrhythmia (jet lag).

- Alcohol and caffeinated beverages should be avoided owing to the risk of dehydration, and adequate amounts of water should be taken.

- Airline foods often contain high sodium. The increased sodium load could present problems for travelers sensitive to volume shifts (e.g., in congestive heart failure)

- The most widely available decongestants carry the risk of raising the blood pressure and should be avoided.

- Sedative-hypnotics drugs should not be used.

- Constrictive clothing around waist and lower extremities should be avoided.

- Simple regular şexion and extension exercises of the lower extremities should be performed to maintain circulation.

- Travelers should get up and walk around every two hours.

- The cabin crew should be informed in case of serious cardiac complaints.

acceleration and deceleration, and aircraft noise have been shown to negatively affect the mood state of the crew (11). These factors should be regarded as confounders for changes in blood pressure, both in passengers and flight crew.

Unfortunately, most data regarding changes in cardiac responses during flight were derived either from retrospective studies or small observational trials. In a recent study (12), 12 men without any known cardiac disease or coronary risk factors were monitored in commercial flights. A decrease in arterial oxygen saturation was observed during the flight when compared with baseline, with the lowest saturation recorded at 120 minutes in cruise altitude. The heart rates were similar at different times of the flight, and the maximum SBP and DBP values were recorded at the time of takeoff. The lowest SBP and DBP values were measured at cruise altitude. Oliveira-Silva et al. (13) have monitored 22 physically active men, free from pathological conditions and medications during commercial flights. They reported $24 \%$ elevated heart rate, $6 \%$ increase in blood pressure, and reduced parameters of heart rate variability.

Furthermore, important cardiovascular responses are less understood and reported during spaceflights. Norsk et al. (14) have observed male astronauts and demonstrated that weightlessness in space initially induced an increase in stroke volume and cardiac output by $35 \%-41 \%$ between 3 and 6 months, accompanied by unchanged or slightly reduced blood pressure by $8-10 \mathrm{~mm} \mathrm{Hg}$ mainly owing to decrease in systemic vascular resistance.

Despite differences in the civil aviation authority rules among countries, some cardiovascular conditions are generally accepted to be a contraindication for air travel $(7,8,15,16)$. Some examples are unstable chest pain, recent myocardial infarction, or cerebrovascular event (within the previous 2 weeks), decompensated heart failure, poorly controlled arrhythmias, uncontrolled hypertension, or pregnancy with preeclampsia. There is no cut-off blood pressure value for "uncontrolled hypertension." However, patients with a value of greater than $180 / 120 \mathrm{~mm} \mathrm{Hg}$ as well as those with dizziness, chest pain, confusion, severe headache, and visual problems must seek specific care. General recommendations for air travelers with hypertension are listed in Table 1. Apart from air travelers, the flight crew, particularly pilots with elevated blood pressure. Should be evaluated and managed carefully according to the instructions from the national civil aviation authorities. Overall, pilots with well-controlled hypertension (central acting agents such as reserpine and methyldopa are prohibited) and without any end-organ damage are not suspended from flying (16).

\section{Conclusion}

The number of air travelers with cardiac diseases is continuing to increase. All passengers with cardiovascular disease should take tailored advice based on their current status. Highaltitude exposure is well tolerated by the hypertensive except for those with uncontrolled blood pressure levels and/or with accompanying serious cardiovascular problems. These patients must seek specific advice from their physician. General recommendations should be followed by the passengers and the flight crew for trouble-free air travel.

Conflict of interest: None declared.

\section{References}

1. Williams B, Mancia G, Spiering W, Agabiti Rosei E, Azizi M, Burnier M, et al.; ESC Scientific Document Group. 2018 ESC/ESH Guidelines for the management of arterial hypertension. Eur Heart J 2018; 39: 3021-104. [Crossref]

2. NCD Risk Factor Collaboration (NCD-RisC). Worldwide trends in blood pressure from 1975 to 2015: a pooled analysis of 1479 population-based measurement studies with 19.1 million participants. Lancet 2017; 389: 37-55.

3. Sengul S, Akpolat T, Erdem Y, Derici U, Arici M, Sindel S, et al.; Turkish Society of Hypertension and Renal Diseases. Changes in hypertension prevalence, awareness, treatment, and control rates in Turkey from 2003 to 2012. J Hypertens 2016; 34: 1208-17. [Crossref]

4. Possick SE, Barry M. Air travel and cardiovascular disease. J Travel Med 2004; 11: 243-8. [Crossref]

5. Sand M, Bechara FG, Sand D, Mann B. Surgical and medical emergencies on board European aircraft: a retrospective study of 10189 cases. Crit Care 2009; 13: R3. [Crossref]

6. Higgins JP, Tuttle T, Higgins JA. Altitude and the heart: is going high safe for your cardiac patient? Am Heart J 2010; 159: 25-32. [Crossref]

7. Silverman D, Gendreau M. Medical issues associated with commercial flights. Lancet 2009; 373: 2067-77. [Crossref]

8. Hofstetter L, Scherrer U, Rimoldi SF. Altitude exposure is not a contraindication for patients with heart disease in general. Going to high altitude with heart disease. Cardiovascular Medicine 2017; 20: 87-95. [Crossref] 
9. Savonitto S, Cardellino G, Doveri G, Pernpruner S, Bronzini R, Milloz $\mathrm{N}$, et al. Effects of acute exposure to altitude $(3,460 \mathrm{~m})$ on blood pressure response to dynamic and isometric exercise in men with systemic hypertension. Am J Cardiol 1992; 70: 1493-7. [Crossref]

10. Palatini P, Businaro R, Berton G, Mormino P, Rossi GP, Racioppa A, et al. Effects of low altitude exposure on 24-hour blood pressure and adrenergic activity. Am J Cardiol 1989; 64: 1379-82. [Crossref]

11. Chandra A, Conry S. In-flight Medical Emergencies. West J Emerg Med 2013; 14: 499-504. [Crossref]

12. Arazi HC, Waldman S, Casso N, Abello M. Hemodynamic Effects of Commercial Flights. Potential Implication on Patients. Clin Surg 2017; 2: 1389
13. Oliveira-Silva I, Leicht AS, Moraes MR, Simões HG, Del Rosso S, Córdova $\mathrm{C}$, et al. Heart Rate and Cardiovascular Responses to Commercial Flights: Relationships with Physical Fitness. Front Physiol 2016; 7: 648. [Crossref]

14. Norsk P, Asmar A, Damgaard M, Christensen NJ. Fluid shifts, vasodilatation and ambulatory blood pressure reduction during long duration spaceflight. J Physiol 2015; 593: 573-84. [Crossref]

15. Smith D, Toff W, Joy M, Dowdall N, Johnston R, Clark L, et al. Fitness to fly for passengers with cardiovascular disease. Heart 2010 Aug; 96 Suppl 2: ii1-16. [Crossref]

16. Oğuz AK. Uçuş hekimliği ve hipertansiyon. Türk Kardiyoloji Seminerleri 2015; 15: 163-71. [Turkish] 